\title{
The challenge of dietary change - insights from national food purchase data
}

\author{
K. L. Barton ${ }^{1}$, W. L. Wrieden ${ }^{2}$, J. Armstrong ${ }^{3}$, A. Sherriff ${ }^{4}$ and A. S. Anderson ${ }^{1}$ \\ ${ }^{1}$ Centre for Public Health Nutrition Research, University of Dundee, Dundee DD1 9SY, ${ }^{2}$ School of Pharmacy and Life \\ Sciences, Robert Gordon University, Aberdeen, AB25 $1 \mathrm{HG},{ }^{3}$ School of Life Sciences, Glasgow Caledonian University, \\ Glasgow G4 OBA and ${ }^{4}$ University of Glasgow Dental School, Glasgow G2 3JZ
}

Trends in population food and nutrient intakes towards the evidence based Scottish Dietary Targets (SDTs) ${ }^{(1)}$ have been monitored from 2001-2009 using secondary analysis of the Living Costs and Food Survey (LCF).

Household food purchase data for Scotland from the UK LCF (Expenditure and Food Survey (EFS) until 2008) was analysed to estimate intakes of foods and nutrients targeted for change in Scotland over the period 2001 to 2009. In addition, data were examined for differences by socioeconomic status measured by the Scottish Index of Multiple Deprivation (SIMD). Adjustments were made to allocate the correct proportion of each food to the appropriate food group (including composite foods), for waste ${ }^{(2,3)}$, and for weight increase or loss due to cooking or dilution. Data were analysed using general linear models within the complex samples module of SPSS (SPSS Inc., Chicago, IL, USA) weighting to the Scottish population and taking account of sampling methods. Results are presented as population means (i.e. consumers and non-consumers) for household and eating out foods combined.

\begin{tabular}{|c|c|c|c|c|c|c|}
\hline Target Food / Nutrient & Scottish Dietary Target ${ }^{1}$ & 2001 & 2009 & $\begin{array}{c}\text { Change Between } \\
2001 \& 2009\end{array}$ & $\begin{array}{l}P \text { for Linear } \\
\text { Association }\end{array}$ & $\begin{array}{c}\text { Highest Consumption } \\
\text { by SIMD }\end{array}$ \\
\hline Fruit and Vegetables & More than $400 \mathrm{~g}$ per day & $239 \mathrm{~g}$ & $257 \mathrm{~g}$ & $\uparrow$ & 0.009 & Least Deprived \\
\hline Bread (all types) & $154 \mathrm{~g}$ per day & $101 \mathrm{~g}$ & $87.3 \mathrm{~g}$ & $\downarrow$ & $<0.001$ & Most Deprived \\
\hline Brown/Wholemeal Bread & More than, $77 \mathrm{~g}$ per day & $16.1 \mathrm{~g}$ & $19.2 \mathrm{~g}$ & $\uparrow$ & $<0.001$ & Least Deprived \\
\hline Breakfast Cereals (all types) & $34 \mathrm{~g}$ per day & $19.5 \mathrm{~g}$ & $23.2 \mathrm{~g}$ & $\uparrow$ & 0.011 & Least Deprived \\
\hline Oil Rich Fish & $88 \mathrm{~g}$ per week & $28.2 \mathrm{~g}$ & $29.5 \mathrm{~g}$ & No Change & NS & Least Deprived \\
\hline White Fish & No decrease (g per week) & $92.9 \mathrm{~g}$ & $89.5 \mathrm{~g}$ & No Change & NS & Least Deprived \\
\hline Fat & $\leq 35 \%$ food energy & $39.2 \%$ & $39.3 \%$ & No Change & NS & No Difference \\
\hline Saturated Fat & $\leq 11 \%$ of food energy & $15.7 \%$ & $15.3 \%$ & $\downarrow$ & 0.003 & No Difference \\
\hline NMES & Adults - No $\uparrow$ Children $-<10 \%$ & $15.6 \%$ & $15.0 \%$ & $\downarrow$ & 0.022 & Most Deprived \\
\hline Total Complex Carbohydrates & $155 \mathrm{~g}$ per day & $138 \mathrm{~g}$ & $138 \mathrm{~g}$ & No Change & NS & No Difference \\
\hline
\end{tabular}

${ }^{1}$ Figures deduced from targets.

${ }^{2}$ SIMD $=$ Social Index of Multiple Deprivation, for combined years 2001-2003, 2004-2006 or 2007-2009.

A standardised methodology has been used to calculate food and nutrient intakes for Scotland on a population basis. The results provide evidence that if trends continue with data for 2010 the SDTs will not have been met by the 2010 target. Clear inequalities are apparent, however, there is no evidence to suggest that the gap between the most and least deprived is increasing with the same very small improvements being seen across all quintiles of SIMD. This monitoring work is of great importance in monitoring dietary goals, and the results for fat, saturated fat and added sugars (NMES) intake are included as Indicators to Monitor Progress of the Obesity Route Map ${ }^{(4)}$. The results from this work can be further used to inform future policy to target diet and social inequalities.

Funded by the Food Standards Agency Scotland and Scottish Government Project no. FS4240180. Data provided by DEFRA, Scottish Neighborhood Statistics, ONS and the UK Data Archive

1. The Scottish Office (1996) Scotland's health a challenge to us all. Eating for Health. A diet action plan for Scotland. Edinburgh: HMSO.

2. Department of Environment, Food and Rural Affairs/Office for National Statistics (2008) Family Food. A Report on the 2007 Expenditure and Food Survey. London: The Stationery Office.

3. Waste and Resource Action Programme (2007) The food we waste. Oxon: WRAP

4. Scottish Government (2011) Indicators to Monitor Progress of the Obesity Route Map. http://www.scotland.gov.uk/Resource/Doc/346011/0115167.pdf 